\title{
Quantification of subsurface heat storage in a GCM simulation
}

\author{
Andrew H. MacDougall, ${ }^{1}$ J. Fidel González-Rouco, ${ }^{2}$ M. Bruce Stevens, ${ }^{1}$ \\ and Hugo Beltrami ${ }^{1}$
}

Received 9 May 2008; accepted 3 June 2008; published 4 July 2008.

[1] Shallow bottom boundary conditions (BBCs) in the soil components of general circulation models (GCMs) impose artificial limits on subsurface heat storage. To assess this problem we estimate the subsurface heat content from two future climate simulations and compare to that obtained from an offline soil model (FDLSM) driven by GCM skin temperatures. FDLSM is then used as an offline substitute for the subsurface of the GCM ECHO-G. With a 600-m $\mathrm{BBC}$ and driven by ECHO-G future temperatures, the FDLSM subsurface absorbs 6.2 (7.5) times more heat than the ECHO-G soil model (10 $\mathrm{m}$ deep) under the Intergovernmental Panel on Climate Change (IPCC) A2 (B2) emission scenario. This suggests that shallow BBCs in GCM simulations may underestimate the heat stored in the subsurface, particularly for northern high latitudes. This effect could be relevant in assessing the energy balance and climate change in the next century. Citation: MacDougall, A. H., J. F. González-Rouco, M. B. Stevens, and H. Beltrami (2008), Quantification of subsurface heat storage in a GCM simulation, Geophys. Res. Lett., 35, L13702, doi:10.1029/ 2008GL034639.

\section{Introduction}

[2] General Circulation Models (GCMs) are the primary tools for estimating the magnitude of future climate change and for assessing its impact on society [Intergovernmental Panel on Climate Change (IPCC), 2007]. One focus of climate modelling is on the degree of realism with which the subsurface thermal regime is reproduced. This is necessary because regional climate models have shown that airground interactions are crucial in adequately reproducing interannual variability in simulated climates [Seneviratne et al., 2006]. Furthermore, the subsurface thermal regime, soil moisture and specific hydrological processes [Bense and Kooi, 2004; Ferguson et al., 2006] are relevant parameters in air-ground interactions, particularly for soil greenhouse gases emissions as a potential climate feedback [Risk et al., 2002a, 2002b; Kellman et al., 2007; Riveros-Iregui et al., 2007]. Therefore, a realistic representation of air-ground interactions in GCMs is necessary to obtain a realistic simulation of the energy balance at the surface and related climate feedbacks in temperature, precipitation, evapotranspiration, convection and regional circulation [Dirmeyer,

\footnotetext{
${ }^{1}$ Environmental Sciences Research Centre, St. Francis Xavier University, Antigonish, Nova Scotia, Canada.

${ }^{2}$ Departamento de Astrofísica y Ciencias de la Atmósfera, Universitas Complutense de Madrid, Madrid, Spain.
}

Copyright 2008 by the American Geophysical Union. 0094-8276/08/2008GL034639
2000; Zhu and Liang, 2005; Seneviratne et al., 2006; Davin et al., 2007; Fischer et al., 2007; Miguez-Macho et al., 2005, 2007].

[3] Support for the importance of understanding the energy exchange processes at the air-ground interface comes from recent analyses of continental subsurface temperatures showing that the continents have globally absorbed about $9 \times 10^{21} \mathrm{~J}$ during the latter half of the 20th century [Beltrami, 2002; Beltrami et al., 2002, 2006; Huang, 2006]. This amount of energy is comparable to that absorbed by the whole atmosphere during the same period [Levitus et al., 2005; IPCC, 2007]. The magnitude of the subsurface heat gain reveals that the continental subsurface is an important energy reservoir in Earth's overall energy budget. Furthermore, the properties of heat conduction make subsurface heat a potentially robust metric in estimating Earth's energy imbalance [Hansen et al., 2005; GonzálezRouco et al., 2008]. It is therefore of interest to investigate how well the subsurface thermal field is simulated in GCMs.

[4] A number of recent studies have investigated aspects of subsurface thermodynamic models. Results show an important sensitivity of heat storage to the placement of the bottom boundary condition (BBC). The current generation of GCM soil model components have BBCs at depths between 1 and $10 \mathrm{~m}$. Placement of BBCs at these depths perturbs both the amplitude and phase of downward propagating sinusoidal signals ranging from 0 to almost $100 \%$ depending on the frequency of the oscillation [Smerdon and Stieglitz, 2006; González-Rouco et al., 2008]. Other studies indicate that shallow BBCs used in GCMs impose an artificial limit to the amount of heat that can be absorbed by the subsurface. In a theoretical experiment, the BBC problem was investigated by Stevens et al. [2007] using a one-dimensional soil model to estimate the influence of the $\mathrm{BBC}$ placement on subsurface heat storage. Using a single grid point forced with ECHO-G Northern Hemispheric average temperatures, Stevens et al. [2007] showed that a shallow BBC of $10 \mathrm{~m}$ depth displaces $75 \%$ of the energy that could have been absorbed by the subsurface if a suitable BBC depth had been used. The study recommends that to properly model the subsurface heat storage potential, $\mathrm{BBCs}$ should be placed at depths at which a change of temperature at the surface does not penetrate sufficiently deep to interfere with subsurface heat storage for the duration of the run.

[5] An unrealistic representation of the simulated subsurface, with limited capacity for heat storage, could affect the simulation of crucial land-atmosphere interactions, such as those driving permafrost stability [Lawrence and Slater, 2005; Sushama et al., 2006, 2007; Alexeev et al., 2007]. An evaluation of the heat absorbed by the land-surface compo- 
nent of ECHO-G in Intergovernmental Panel on Climate Change (IPCC) scenario simulations was presented by González-Rouco et al. [2008] and discussed within the context of Stevens et al. [2007].

[6] In this study we compare for the first time the spatial distribution of the energy absorbed by the soil model in a GCM (the ECHO-G) to that of a finite difference landsurface model (FDLSM), driven by the GCM near-surface temperature output as a time varying upper boundary condition. Existing ECHO-G output from two 1000-year paleoclimatic forced simulations and two 110-year future simulations were used for the upper boundary condition. The future simulations were done under the IPCC Special Report on Emission Scenarios (SRES) A2 and B2 [FischerBurns et al., 2005; Zorita et al., 2005; Stevens et al., 2007; González-Rouco et al., 2008].

[7] The approach used here does not take into account potentially significant feedbacks between the land and the atmosphere (e.g. latent and sensible heat exchange, advection, evapotranspiration), but nonetheless the method should yield a good approximation of what the ECHO-G soil model component could have absorbed with a deep BBC. Here, we present the results from experiments that estimate the energy that a deeper GCM soil model component could absorb during the 21 st century as determined from the ECHO-G A2 and B2 future climate projections. The FDLSM was initially run with a BBC at a depth comparable to the ECHO-G soil model $(10 \mathrm{~m})$ to verify that the two soil models are thermodynamically equivalent. The FDLSM was then reconfigured for a deep BBC and the experiment run for the 21st century. Results show that the deep FDLSM run globally captures 6.2 (7.5) times more energy than the ECHO-G soil model for the time period 1991-2100 CE under the A2 (B2) scenario. Under each scenario, the largest difference between the ECHO-G and deep FDLSM heat absorption occurs in high northern latitudes. These results suggest that shallow BBCs in GCMs prevent large amounts of heat from being stored in the subsurface. This effect could have relevance in assessing the magnitude of change in surface temperature in simulations of future climate.

\section{Model Descriptions}

[8] The GCM ECHO-G is a coupled climate model consisting of the atmospheric component ECHAM4, and the ocean component HOPE-G. ECHO-G has 1104 nonglaciated land-surface grid points, at a T30 resolution $\left(3.75^{\circ}\right.$ lat $\times$ lon, or circa $300 \times 300 \mathrm{~km}$ at $45^{\circ}$ lat $)$. The glacial land-surface grid points are not included in subsequent analysis. The ECHO-G soil model has thermal properties that are spatially invariant, and five vertical layers that increase in thickness with depth to $9.834 \mathrm{~m}$. The model uses a uniform thermal diffusivity of $\kappa=7.5 \times 10^{-7} \mathrm{~m}^{2} \mathrm{~s}^{-1}$ and heat capacity per unit volume of $\rho_{g} C_{g}=2.4 \times 10^{6}$ $\mathrm{Jm}^{-3} \mathrm{~K}^{-1}$ [Legutke and Voss, 1999].

[9] There exist two 1000-year forced simulations for the GCM ECHO-G and a control simulation with constant present-day forcing. The two millennium forced runs were produced with different initial conditions but the same forcing based on estimates of solar variability, greenhouse gas concentrations and stratospheric volcanic aerosols
(FOR1 and FOR2, as labeled by González-Rouco et al. [2008]). The FOR1 simulation is used in this work and continues until the end of the 21 st century under the IPCC A2 and B2 scenarios. For additional details and extensive model verification of the GCM ECHO-G see GonzálezRouco et al. [2008, and references therein].

[10] The FDLSM was originally designed to study snowground thermal interactions and the thermal regime of the subsurface. The only heat transfer mechanism in the simulated subsurface is assumed to be heat conduction; latent heat effects and freeze/thaw events are neglected. Both the thermophysical properties of the simulated subsurface and the upper and lower boundaries of the model need to be prescribed. The lower boundary condition can be placed at a specific depth and constrained by either constant temperature or heat flux [Goodrich, 1982; Stevens et al., 2007]. For this study we used a zero flux BBC as in the ECHO-G soil model. FDLSM has a discretization error of approximately $2 \%$.

\section{Analysis}

[11] The change in subsurface heat storage within the GCM ECHO-G for the 21 st century was calculated using the simulated soil temperatures from the five layers of the soil model component. The heat content was calculated for every time step at monthly resolution for each grid point over all continental areas as in work by González-Rouco et al. [2008]:

$$
Q_{s}=\rho_{g} C_{g} \sum_{i=1}^{5} T(i) \Delta z(i)
$$

where $Q_{s}$ is the subsurface heat storage in $\mathrm{Jm}^{-2}, \rho_{g} C_{g}$ is the volumetric heat capacity in $\mathrm{Jm}^{-3} \mathrm{~K}^{-1}, T$ is temperature of the layer in $K$ and $\Delta z$ is the thickness of the layer in $m$. The change in subsurface heat storage was estimated as the difference in total heat between the first and the last time step in the ECHO-G soil model future scenario output. This process was repeated for all of the continental grid points in ECHO-G under both the A2 and B2 scenario simulations.

[12] The FDLSM was used first with a zero flux BBC placed at a depth of $10 \mathrm{~m}$ with thermal properties identical to those of the ECHO-G soil model. The model was reconfigured with a deep $\mathrm{BBC}(600 \mathrm{~m}$ depth) and thermal properties identical to those used in ECHO-G in the top $10 \mathrm{~m}$ and those of rock below $10 \mathrm{~m}$. For the rock layer the thermal properties were $\kappa=1 \times 10^{-6} \mathrm{~m}^{2} \mathrm{~s}^{-1}$ and $\rho_{g} C_{g}=$ $3 \times 10^{6} \mathrm{~m}^{-3} \mathrm{~K}^{-1}$ [Cermak and Rybach, 1982]. For two different homogeneous media, the relationship between heat storage and thermal properties is given by:

$$
Q_{1}=\frac{\rho_{1} C_{1} \sqrt{\kappa_{1}}}{\rho_{2} C_{2} \sqrt{\kappa_{2}}} Q_{2},
$$

where $\mathrm{Q}$ is heat storage $\left(\mathrm{Jm}^{-2}\right), \rho C$ is volumetric heat capacity $\left(\mathrm{Jm}^{-3} \mathrm{~K}^{-1}\right)$, and $\kappa$ is thermal diffusivity $\left(\mathrm{m}^{2} \mathrm{~s}^{-1}\right)$ of medium 1 or 2 , as subscripted. It is therefore possible to scale the quantitative results of this work to a different set of thermal properties by applying equation (2). 
[13] A BBC depth of $600 \mathrm{~m}$ is well beyond the $150-$ $200 \mathrm{~m}$ depth [Stevens et al., 2007] recommends for centennial simulations. In both FDLSM configurations the temperatures from the shallowest layer of the ECHO-G soil model were used as the time varying upper boundary condition of the FDLSM.

[14] The original thermal state of the subsurface at each grid point is an isothermal temperature profile, set to the mean temperature of the shallowest layer of the ECHO-G soil model for the 1000-1990 CE simulation. The FDLSM was allowed to spin-up for 1000 years using the FOR1 simulation as the upper boundary condition. At the end of the spin-up period the temperature-depth profile produced was used as the initial condition for the 1991-2100 CE future simulation. This procedure was used for all the $21 \mathrm{st}$ century simulations considered here. The ECHO-G A2 and B2 scenario simulations were used at each grid point in nonglaciated continental areas as the time varying upper boundary condition for the FDLSM. At the end of this interval the FDLSM yields the final subsurface thermal state.

[15] The subsurface heat storage in the FDLSM was estimated by the Riemann sum of the subsurface temperatures given by:

$$
Q_{s}=\Delta z \sum_{i=1}^{d-1} \frac{(T(i)+T(i+1))}{2} C_{v}(i),
$$

where $Q_{s}$ is the subsurface heat storage in $\mathrm{Jm}^{-2}, d$ is the total number of nodes in the profile, $C_{v}$ is the volumetric heat capacity in $\mathrm{Jm}^{-3} \mathrm{~K}^{-1}, T$ is the temperature of the layer in $K$ and $\Delta z$ is the inter-nodal spacing in $m$.

[16] The total heat storage was calculated as the difference between the final and initial subsurface thermal states from the 1991-2100 simulation. The above experiments were conducted for both the A2 and B2 scenarios. The results for the A2 (B2) scenario are detailed in the next section and shown in Table 1 and in Figures 1a, 1b, and 1c (Table 1 and in Figures 1d, 1e, and 1f).

\section{Results and Discussion}

[17] The change in $Q_{s}$ in the ECHO-G A2 scenario simulation for the $21 \mathrm{st}$ century is shown in Figure 1a [González-Rouco et al., 2008] and for the B2 scenario in Figure 1d. The A2 scenario global mean heat gain is $1.25 \times$ $10^{8} \mathrm{Jm}^{-2}$ and the total cumulative continental heat gain is $1.58 \times 10^{22} \mathrm{~J}$ (see Table 1 for details.) This quantity of heat is on the same order as the heat gained by the continental land surface during the second half of the 20th century $(0.9 \times$ $\left.10^{22} \mathrm{~J}\right)$ [Beltrami, 2002]. Considering the large increase in global average temperature relative to the change during the 20th century in the ECHO-G A2 simulation, the subsurface would be expected to absorb far more heat during the $21 \mathrm{st}$ century than during the 20th century.

[18] The mean change in $Q_{s}$ simulated by the FDLSM with a $10 \mathrm{~m} \mathrm{BBC}$ under the A2 scenario is estimated to be $1.3 \times 10^{8} \mathrm{Jm}^{-2}$ and the total cumulative continental heat gain is $1.6 \times 10^{22} \mathrm{~J}$ (see Table 1). Shown in Figure $1 \mathrm{~b}$ for the A2 scenario and Figure 1e for the B2 scenario is the ratio of the ECHO-G subsurface heat and subsurface heat from the $10 \mathrm{~m}$ BBC FDLSM experiment; the frequency distribution of the grid point specific ratios is shown in the inset. The ratios under A2 range from 0.91 to 1.11, with a mean of 1.00 and a standard deviation of 0.027 . These ratios are very close to unity considering the FDLSM's 2\% computation error and the different algorithms used in the two models.

[19] Overall the ECHO-G soil model and FDLSM with a $10 \mathrm{~m} \mathrm{BBC}$ have nearly identical changes in heat over the 21 st century (see Figures $1 \mathrm{~b}$ and $1 \mathrm{e}$ ). With this agreement in the top $10 \mathrm{~m}$ of the subsurface it is reasonable to assume that the behaviour of the FDLSM remains stable at greater depths, such that the FDLSM can be used as an offline tool for carrying out experiments that would otherwise not be possible because of computational and budgetary restrictions. In this study we used the FDLSM to estimate the potential subsurface heat storage of a GCM simulation with a deep BBC.

[20] The mean change in $Q_{s}$ simulated by a FDLSM with a deep BBC under the $\mathrm{A} 2$ scenario is estimated to be $7.8 \times$ $10^{8} \mathrm{Jm}^{-2}$ and total cumulative continental heat gain is $9.8 \times$ $10^{22} \mathrm{~J}$ (see Table 1). This total continental heat gain is 6.2 (7.7) times that absorbed by the subsurface of the GCM ECHO-G under the A2 (B2) scenario.

[21] The spatial distribution of subsurface heat accumulation was broadly similar for all of the models under the A2 scenario, but with large differences in the magnitude of heat accumulation between the shallow $\mathrm{BBC}$ runs and the FDLSM with a deep BBC. The most notable pattern is that the largest heat accumulation occurs in the high northern latitudes, particularly in Eurasia. Also of note is the area of less intense heat accumulation over the pacific coast of North America and a general trend for low precipitation regions to have higher heat accumulation than surrounding areas.

[22] Shown in Figure 1g is the timeseries of total continental subsurface heat accumulation as simulated by ECHO-G and the deep FDLSM experiment, for both the A2 and B2 scenarios. The difference between the ECHO-G subsurface heat accumulation and that of the FDLSM experiment under the A2 scenario is 13 times larger than the difference in subsurface heat storage between the A2 and $\mathrm{B} 2$ scenarios in the ECHO-G soil model. This demonstrates that the $\mathrm{BBC}$ position is more important in determination of subsurface heat storage than the choice of future emissions scenario, as suggested by González-Rouco et al. [2008]. The difference in the magnitude of heat absorbed by ECHO-G's soil model and the deep FDLSM under the A2 scenario $\left(8.2 \times 10^{22} \mathrm{~J}\right)$ is quite significant within the context of Earth's energy budget. Over the period 1955-2003 CE the oceans absorbed an estimated $14.2 \times 10^{22} \mathrm{~J}$, while the atmosphere absorbed $0.5 \times 10^{22} \mathrm{~J}$ [Levitus et al., 2005; IPCC, 2007].

[23] Clearly, if even a small portion of the heat that could have been stored in the ground was redirected to the atmosphere, simulated energy budgets, land surface, and biogeochemical processes could be affected. Of particular concern is the possible effect on simulated permafrost degradation, as the largest differences between ECHO-G heat storage and heat storage in the deep FDLSM experiment occur at high northern latitudes as shown in Figures 1c and $1 \mathrm{f}$. We cannot calculate the exact amount nor the destination of heat that could have been stored in the subsurface because of the absence of GCM feedback mechanisms, which are not included in our first order estimates. 

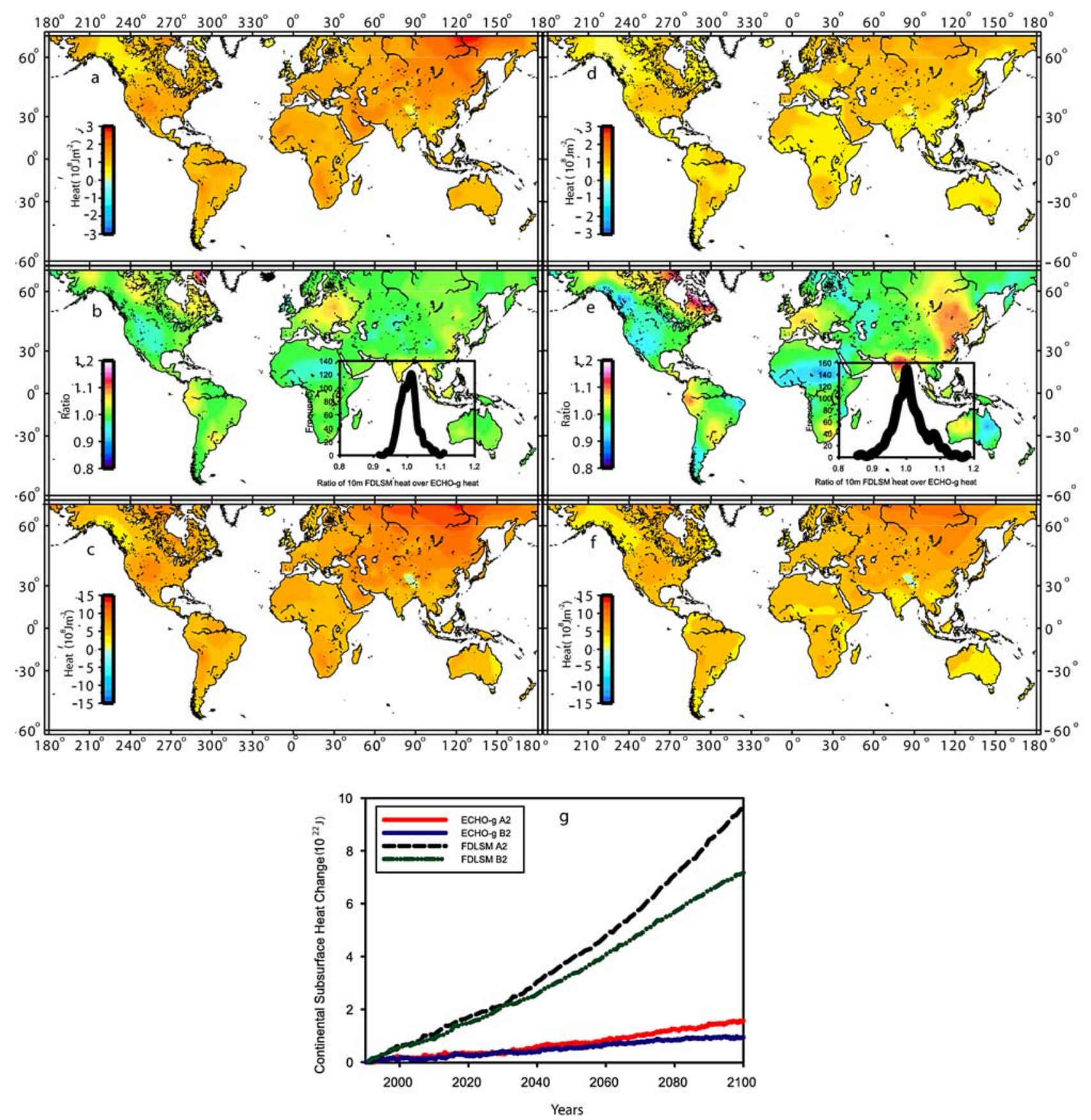

Figure 1. (a) Change in ECHO-G subsurface heat storage during the 21st century for the IPCC A2 emission scenario simulation. (b) Ratio between heat storage for ECHO-G and the FDLSM for A2. Inset: Frequency distribution of the grid point to grid point ratio of ECHO-G and $10 \mathrm{~m}$ FDLSM. (c) Difference in heat between the deep FDLSM experiment and ECHO-G under A2. (d, e, and f) Same as Figures 1a, 1b, and 1c, respectively, but for B2. (g) Total continental accumulation of subsurface heat (units of $10^{22} \mathrm{~J}$ ) for respective scenarios and experiments. Units are $10^{8} \mathrm{~J} / \mathrm{m}^{2}$ for Figures $1 \mathrm{a}$, $1 \mathrm{c}, 1 \mathrm{~d}$, and $1 \mathrm{f}$.

Underestimation of subsurface heat storage due to shallow $\mathrm{BBC}$ placements is likely not specific to ECHO-G, which in fact has the deepest BBC among its generation of GCMs and as such it should be taken as the best case scenario.

\section{Conclusions}

[24] When driven by ECHO-G near-surface temperatures and using the same BBC depth as the ECHO-G soil model, the FDLSM can reproduce the heat absorbed by ECHOG's subsurface such that it can be used as a subsurface proxy in further offline experiments. Given a deep BBC depth, the FDLSM absorbed 6.2 (7.7) times as much heat as the subsurface of ECHO-G under the A2 (B2) scenario. The difference between the heat absorbed by the subsurface of ECHO-G and the FDLSM with a deep BBC is the most extreme at northern high latitudes; these results may therefore be relevant to the simulation of permafrost degradation in the 
Table 1. Summary Table of Statistics for the ECHO-G Soil Model and the FDLSM Under the A2 and B2 Scenario Simulations ${ }^{\mathrm{a}}$

\begin{tabular}{lccc}
\hline & ECHO-G & 10 m FDLSM & $600 \mathrm{~m}$ FDLSM \\
\hline & \multicolumn{3}{c}{ Scenario A2 } \\
Mean & 1.245 & 1.248 & 7.791 \\
Std dev. & 0.523 & 0.528 & 3.468 \\
Min. & -0.0545 & -0.0544 & - \\
Max. & 3.035 & 3.120 & - \\
Total & 1.58 & 1.58 & 9.80 \\
& & & \\
Mean & 0.763 & Scenario B2 & 5.796 \\
Std Dev. & 0.332 & 0.766 & 2.689 \\
Min. & -0.0570 & -0.0569 & - \\
Max. & 2.085 & 2.058 & - \\
Total & 0.97 & 0.97 & 7.27 \\
\hline
\end{tabular}

${ }^{\mathrm{a}}$ Mean, standard deviation, minimums and maximums are expressed as $10^{8} \mathrm{Jm}^{-2}$. Total global cumulative heat storage is in $10^{22} \mathrm{~J}$. Results from the FDLSM have an associated computational error of $2 \%$.

21 st century. Under the A2 scenario, this difference in heat was 13 times larger than the difference in subsurface heat absorption between the A2 and B2 ECHO-G scenario simulations; this result suggests that the placement of the $\mathrm{BBC}$ is more important in simulating subsurface heat absorption than the future emission scenario used.

[25] In the future, climate change scenario simulations should use deep BBC placements or incorporate bottom boundary condition algorithms that mimic the heat storage properties of the deep subsurface, such as using a negative flux BBC that would allow heat to escape the bottom boundary.

[26] Acknowledgments. This research was funded by grants from NSERC Discovery, AIF (ACOA), CFCAS, and ACEnet (HB); Ramon y Cajal (JFGR); NSERC PGS-D (MBS); and NSERC USRA (AHM).

\section{References}

Alexeev, V. A., D. J. Nicolsky, V. E. Romanovsky, and D. M. Lawrence (2007), An evaluation of deep soil configurations in the CLM3 for improved representation of permafrost, Geophys. Res. Lett., 34, L09502, doi:10.1029/2007GL029536.

Beltrami, H. (2002), Climate from borehole data: Energy fluxes and temperatures since 1500, Geophys. Res. Lett., 29(23), 2111, doi:10.1029/ 2002GL015702.

Beltrami, H., J. E. Smerdon, H. N. Pollack, and S. Huang (2002), Continental heat gain in the global climate system, Geophys. Res. Lett., 29(8), 1167, doi:10.1029/2001GL014310.

Beltrami, H., E. Bourlon, L. Kellman, and J. F. González-Rouco (2006), Spatial patterns of ground heat gain in the Northern Hemisphere, Geophys. Res. Lett., 33, L06717, doi:10.1029/2006GL025676.

Bense, V. F., and H. Kooi (2004), Temporal and spatial variations of shallow subsurface temperature as a record of lateral variations in groundwater flow, J. Geophys. Res., 109, B04103, doi:10.1029/2003JB002782.

Cermak, V., and L. Rybach (1982), Thermal conductivity and specific heat of minerals and rocks, in Physikalische Eigenschaften der Gesteine, Landolt-Börnstein Zahlenwerte Funkt. Naturwiss. Tech., vol. 1, edited by G. Angenheister, pp. 305-343, Springer, Berlin.

Davin, E. L., N. de Noblet-Ducoudré, and P. Friedlingstein (2007), Impact of land cover change on surface climate: Relevance of the radiative forcing concept, Geophys. Res. Lett., 34, L13702, doi:10.1029/ 2007GL029678.

Dirmeyer, P. A. (2000), Using a global soil wetness dataset to improve seasonal climate simulation, J. Clim., 13, 2900-2922.

Ferguson, G., H. Beltrami, and A. D. Woodbury (2006), Perturbation of ground surface temperature reconstructions by groundwater flow?, Geophys. Res. Lett., 33, L13708, doi:10.1029/2006GL026634.

Fischer, E. M., S. I. Seneviratne, D. Lüthi, and C. Schär (2007), Contribution of land-atmosphere coupling to recent European summer heat waves, Geophys. Res. Lett., 34, L06707, doi:10.1029/2006GL029068.
Fischer-Bruns, I., H. von Storch, J. F. González-Rouco, and E. Zorita (2005), A modelling study on the variability of global storm activity on timescales of decades and centuries, Clim. Dyn., 25, 461-476.

González-Rouco, J. F., H. Beltrami, E. Zorita, and M. B. Stevens (2008), Borehole climatology: A discussion based on contributions from climate modeling, Clim. Past Discuss., 4, 1-80.

Goodrich, L. E. (1982), The influence of snow cover on the ground thermal regime, Can. Geotech. J., 19, 421-432.

Hansen, J., et al. (2005), Earth's energy imbalance: Confirmation and implications, Science, 308, 1431-1435.

Huang, S. (2006), 1851-2004 annual heat budget of the continental landmasses, Geophys. Res. Lett., 33, L04707, doi:10.1029/2005GL025300.

Kellman, L., H. Beltrami, and D. Risk (2007), Changes in seasonal soil respiration with pasture conversion to forest in Atlantic Canada, Biogeochemistry, 82, 101-109, doi:10.1007/s10 533-006-9056-0.

Lawrence, D. M., and A. G. Slater (2005), A projection of severe nearsurface permafrost degradation during the 21 st century, Geophys. Res. Lett., 32, L24401, doi:10.1029/2005GL025080.

Legutke, S., and R. Voss (1999), The Hamburg Atmosphere-Ocean Coupled Circulation Model ECHO-G, Tech. Rep. 18, Ger. Clim. Comput. Cent., Hamburg, Germany.

Levitus, S., J. Antonov, and T. Boyer (2005), Warming of the world ocean, 1955-2003, Geophys. Res. Lett., 32, L02604, doi:10.1029/ 2004 GL021592.

Miguez-Macho, G., G. L. Stenchikov, and A. Robock (2005), Regional climate simulations over North America: Interaction of local processes with improved large-scale flow, J. Clim., 18, 1227-1246.

Miguez-Macho, G., Y. Fan, C. P. Weaver, R. Walko, and A. Robock (2007), Incorporating water table dynamics in climate modeling: 2. Formulation, validation, and soil moisture simulation, J. Geophys. Res., 112, D13108, doi:10.1029/2006JD008112.

Risk, D., L. Kellman, and H. Beltrami (2002a), Soil $\mathrm{CO}_{2}$ production and surface flux at four climate observatories in eastern Canada, Global Biogeochem. Cycles, 16(4), 1122, doi:10.1029/2001GB001831.

Risk, D., L. Kellman, and H. Beltrami (2002b), Carbon dioxide in soil profiles: Production and temperature dependence, Geophys. Res. Lett., 29(6), 1087, doi:10.1029/2001GL014002.

Riveros-Iregui, D. A., R. E. Emanuel, D. J. Muth, B. L. McGlynn, H. E. Epstein, D. L. Welsch, V. J. Pacific, and J. M. Wraith (2007), Diurnal hysteresis between soil $\mathrm{CO}_{2}$ and soil temperature is controlled by soil water content, Geophys. Res. Lett., 34, L17404, doi:10.1029/ 2007GL030938.

Seneviratne, S. I., D. Lüthi, M. Litschi, and C. Schär (2006), Land-atmosphere coupling and climate change in Europe, Nature, 443, 205-209, doi:10.1038/nature05095.

Smerdon, J. E., and M. Stieglitz (2006), Simulating heat transport of harmonic temperature signals in the Earth's shallow subsurface: Lowerboundary sensitivities, Geophys. Res. Lett., 33, L14402, doi:10.1029/ 2006 GL026816.

Intergovernmental Panel on Climate Change (IPCC) (2007), Climate Change 2007: The Physical Science Basis. Contribution of Working Group I to the Fourth Assessment Report of the Intergovernmental Panel on Climate Change, edited by S. Solomon et al., Cambridge Univ. Press, Cambridge, U. K.

Stevens, M. B., J. E. Smerdon, J. F. González-Rouco, M. Stieglitz, and H. Beltrami (2007), Effects of bottom boundary placement on subsurface heat storage: Implications for climate model simulations, Geophys. Res. Lett., 34, L02702, doi:10.1029/2006GL028546.

Sushama, L., R. Laprise, and M. Allard (2006), Modeled current and future soil thermal regime for northeast Canada, J. Geophys. Res., 111, D18111, doi:10.1029/2005JD007027.

Sushama, L., R. Laprise, D. Caya, D. Verseghy, and M. Allard (2007), An RCM projection of soil thermal and moisture regimes for North American permafrost zones, Geophys. Res. Lett., 34, L20711, doi:10.1029/ 2007GL031385

Zhu, J., and X.-Z. Liang (2005), Regional climate model simulation of U.S. soil temperature and moisture during 1982-2002, J. Geophys. Res., 110, D24110, doi:10.1029/2005JD006472.

Zorita, E., J. F. González-Rouco, H. von Storch, J. P. Montávez, and F. Valero (2005), Natural and anthropogenic modes of surface temperature variations in the last thousand years, Geophys. Res. Lett., 32, L08707, doi:10.1029/2004GL021563.

H. Beltrami, A. H. MacDougall, and M. B. Stevens, Environmental Sciences Research Centre, St. Francis Xavier University, 1 West Street, Antigonish, NS B2G 2W5, Canada. (hugo@stfx.ca)

J. F. González-Rouco, Departamento de Astrofísica y Ciencias de la Atmósfera, Universitas Complutense de Madrid, Madrid E-28040, Spain. 